\title{
BURGUESIA Y NEGOCIOS: LA ESPECULACION EN EL SECTOR SERVICIOS DE LA CIUDAD DE ALICANTE A FINES DEL SIGLO XIX (1880-1900)
}

\author{
JAVIER VIDAL OLIVARES
}

La expansión y afianzamiento, desde la segunda mitad del siglo XIX, de las fuerzas productivas agrarias en el ámbito territorial del País Valenciano configuraron, de manera hegemónica, el crecimiento económico. Este proceso de agrarización progresiva de la estructura económico-social, sancionaba el dilatado período en que se produjo la génesis del capitalismo en el seno de la formación social valenciana; a la vez que, de modo simultáneo, se producía el ascenso y la instalación de las nuevas oligarquías surgidas de la revolución burguesa. ${ }^{1}$

Durante las décadas centrales del Ochocientos, la burguesía en cualquiera de sus fracciones, orientó buena parte de sus capitales hacia la especulación ferroviaria, las sociedades financieras, la compra de tierras o los seguros. ${ }^{2}$ La etapa de fin

1 Vid. Ruiz Torres, P., Historia del País Valenciano, vol. VI, Barcelona, Planeta, 1981, pp: 181-214. Del mismo autor, "La transición al capitalismo en el País Valenciano: ¿Cambio estructural en el siglo XIX?". En Nuestra Historia, vol. VI, Valencia, Mas-Ivars editores, 1982, pp. 87-101.

2 Sobre la especulación ferroviaria en las comarcas centrales del País Valenciano, vid. HeRnÁNDEZ Sempere, T. M., "Diez consideraciones en torno a la construcción de los ferrocarriles de via ancha y el papel de un empresario histórico, José Campo". En Estudis d'Història Contemporània del País Valencià, Universitat de València, Facultat de Geografia i Història, departament d'història contempòrania, 1981, pp. 435-449. Los orígenes de las sociedades financieras de Valencia en RóDENAS, C., Banca $i$ industrialització. El cas Valencià (1840-1880). València, Eliseu Climent, 1978, pp. 59-192. Para la desamortización, BRINES BLASCO, J., La desamortización eclesiástica en el País Valenciano durante el trienio constitucional. Valencia, Universidad de Valencia, 1978. 
de siglo, además de consolidar estas actividades, presenciará el advenimiento de otras nuevas: el relanzamiento del sector servicios en ciudades que crecen y necesitan de innovaciones infraestructurales.

El objetivo de estas páginas no es otro que poner en relación las nuevas necesidades surgidas de la urbanización de la ciudad de Alicante, al compás del aumento poblacional y el proceso paralelo de atracción de capitales. Capitales que provenían, en su mayor parte, de la burguesía comercial alicantina de la época. ${ }^{3}$ En efecto, la expansión vinícola de los años 1880 a 1900 - al socaire del tratado franco-español de 1882-comportó un incremento de ganancias entre cosecheros $y$, singularmente, comerciantes. ${ }^{4}$ Estos últimos, que gozaban de organización propia al detentar los mecanismos y resortes de la Cámara de Comercio, nutrirán las filas de la más genuina "aristocracia financiera". ${ }^{5} \mathrm{Si}$ la colocación dé beneficios se había venido canalizando hacia los valores en deuda pública, el préstamo usurario sobre la propiedad rústica o la banca personal, durante los años finiseculares los grupos burgueses ciudadanos fijaran su atención en negocios que se perfilaban altamente rentables a corto plazo: abastecimiento de agua, establecimiento de una red de tranvías, electricidad y construcción.

Con todo, estas diligencias no restarán protagonismo a las tradicionales fuentes de ingresos de los comerciantes. La ex-

3 Abordamos este tema en nuestra Memoria de Licenciatura inédita. VIDAL OLIVARES, J., Burguesia y Poder. Alicante durante la Restauración (18751905). Valencia, Universidad de Valencia, Facultad de Geografía e Historia, 1983.

4 Importante para la expansión vinícola de finales del siglo XIX, CARNERo ARBAT, T., Expansión vinícola y atraso agrario (1870-1900). Madrid, Ministerio de Agricultura, 1980, pp. 71-102. Respecto a la problemática político económica en Alicante, vid. VIDAL OLIVARES, J., "Algunas aportaciones al estudio de la vida económico y social de la ciudad de Alicante en las postrimerías del siglo XIX (1887-1905)". En Actes del / Congrés d'Estudis del Camp d'Alacant, Alacant, 1982. (En prensa).

5 Utilizamos el concepto "aristocracia financiera", dándole el mismo sentido que el profesor Ernest Lluch, quien lo define como aquel sector de la clase dominante que basa su poder en la especulación, la banca, el oligopolio de la importación y los negocios de una ciudad que crece y necesita de mayores servicios. Vid. LLUCH, E., La vía valenciana, València, Eliseu Climent, 1975 , pp. 117 y ss. 
portación e importación de productos agrarios seguirá ocupando, hegemónicamente, los esfuerzos y preocupaciones de la burguesía mercantil porturia hasta bien entrado el siglo XX.

\section{EL ABASTECIMIENTO DE AGUAS}

El abasto de aguas en la ciudad de Alicante se realizaba, al menos desde el siglo XVIII, a través de los denominados propios del municipio. ${ }^{6}$ En la segunda mitad del XIX, estos pozos se revelaban incapaces de proporionar el caudal necesario para asegurar las necesidades de la urbe, especialmente por la combinación de dos factores: el perceptible incremento de la población y las persistentes sequías. Si en 1866 los manantiales de la Casa Blanca y Valladolid producían mil metros cúbicos diarios, veintiocho años más tarde, en 1894, ambos se habían agotado. ${ }^{7}$

El Ayuntamiento, durante este largo período, no encontraba sino soluciones transitorias para hacer frente a la situación, mientras que la iniciativa privada acudía presta más a conseguir beneficios que a solventar el problema. Hacia 1880, José Carlos de Aguilera y Aguilera - Marqués de Benalúa- inicia los estudios necesarios para acometer la traida de aguas desde la partida de La Alcoraya, obteniendo del Cabildo municipal las autorizaciones pertinentes. Un año después se inaugura el abastecimiento público. Sin embargo, coincidiendo con la consolidación de su concesión, el Marqués traspasa sus derechos a la compañía británica denominada The Alicante Water Work Limited, en el verano de 1883. La operación se realizaba reservándose el de Benalúa un lugar en el Consejo de Administración, lo

6 Las heredades de Valladolid y Cabanes, propios del municipio en el Setecientos, se localizaban en las tierras de regadío del término. Estas tierras consumian parte de su agua en el riego y la restante, mediante un conducto, proveía a las fuentes de la ciudad y sus arrabales. Vid. SAIz PASTOR, C., Abastecimiento y Hacienda Municipal en el Alicante del siglo XVIII. Memoria de Licenciatura inédita. Alicante, Universidad de Alicante, Facultad de Geografía e Historia, 1982, p. 41.

7 Sánchez Santana, E. y Guardiola Picó, J., Memoria higiénica de Alicante, Alicante, Tipografía Costa y Mira, 1894, p. 95. 
cual otorgaba un carácter ciertamente especulativo a la transacción, toda vez que el abastecimiento era de corte monopolista ya que incapacitaba al municipio para establecer otras fuentes en la localidad. Simultáneamente, la compañía inglesa se aseguraba la posibilidad de introducirse en otros sectores de servicios urbanos, como el del gas para alumbrado, como así ocurrió en 1884. El hecho de que la enajenación se realizara sabiéndose "a priori" que los manantiales utilizados resultaban insuficientes, fue un éxito de Benalúa que hizo valer su peso politico en las palancas del poder municipal - había sido teniente de alcalde en el primer Cabildo de la Restauración y capitaneaba el fusionismo sagastino en Alicante-. No obstante, su pretensión de conseguir, durante cincuenta años, el monopolio abastecedor se vio entorpecida por la competencia de otras empresas. En este sentido cabe interpretar las demandas, en 1891, de Enrique Caucurte, propietario de pozos en la villa de Sax, junto a las de otro particular, Victoriano Blasco.

El triunfo de las candidaturas republicanas en las elecciones municipales de 1891 repercutió sensiblemente en el tratamiento del tema. Los republicanos, atentos a la diversificación, entregaron la concesión a Caucurte. El resultado del recurso contencioso que interpuso el Marqués de Benalúa a esta medida se mostró perjudicial para la ciudad, pues mantuvo paralizadas las obras de canalización del propietario de Sax. ${ }^{8}$

La falta de capitales con que se encuentra el Caucurte es el nuevo escollo en el camino. En 1895, se entra en una etapa de enervamiento social en la ciudad, dada la escasez de aguas. Nuevamente los concesionarios entran en conversaciones con capitalistas ingleses, puesto que se reconocía la ausencia de iniciativas autóctonas para colocar numerario en las obras:

(...) Hasta nosotros han llegado rumores de que los propietarios de las aguas de Sax y Villena, destinadas á esta ciudad, teniendo distraidos atención y capitales en otras empresas por su

8 Abastecimiento de Aguas para la ciudad de Alicante. Contestación a la demanda del Sr. Marqués de Benalúa que presenta al Tribunal de lo Contencioso-Administrativo D. Enrique Caucurte y Julliat, redactada por el Ecxmo. Sr. D. Francisco Lastres y Juiz, abogado del llustre Colegio de Madrid, Madrid, Tipografía de los Hijos de M. G. Hernández, 1894, pp. 6-10. 
profesión mercantil les es dificil encontrar en esta región, 6 al menos en España, capitales con los que se pueda llevar á vías de hecho el viaje de las citadas aguas, viendose, pues, en la necesidad de recurrir á una empresa inglesa, que será probablemente la encargada del negocio. ${ }^{9}$

Este pesimismo general de la época no debe empañar las iniciativas esforzadas por construir este tipo de obras, caracterizadas por ser inversiones en capital social fijo. En esta línea contrasta la actitud de Juan Leach Giró. Comercialmente emprendedor, de reconocido prestigio ciudadano, constituye el paradigma del sector burgués más dinámico de la urbe, en el último cuarto de siglo. ${ }^{10} \mathrm{Ya}$, desde 1877, llevaba aguardando el momento propicio para irrumpir con total protagonismo en el negocio del agua. Cuando, en 1895, la cuestión del abastecimiento se encuentra en una situación de total incertidumbre su actuación adquiere un papel relevante.

Leach, comenzó comprando, al Marqués de la Remisa, extensas parcelas de la denominada Laguna de Villena, ubicada en el término municipal del mismo nombre. En 1825, estas tierras habian sido entregadas por don Fernando VII, al hijo del General Elio y, tras la subsiguiente impugnación por las Cortes, se transfirieron a la Junta de Bienes Nacionales de quien, a su vez, adquirieron la propiedad el de Remisa y Segismundo Moret. ${ }^{11}$

9 "De vital interés para Alicante". Boletín de la Cámara de Comercio de Alicante, núm. 64, Alicante, septiembre, 1895, pp. 86-87.

10 Juan Leach Giró, comerciante malagueño afincado en Alicante, de origen angloamericano; poseía un almacen de frutos coloniales, depósitos de hierro al por mayor, y actuaba como exportador de vinos y comisionista. Sus caldos eran muy conocidos en París, Burdeos y Marsella. Fue alcalde de la ciudad, en 1874, como miembro del partido republicano de Castelar. Presidió la Cámara de Comercio en alternancia con Guillermo Campo Carreras. Ejerció el secretariado del Consejo de Administración de la Caja Especial de Ahorros y la dirección de esta entidad, en 1877. Hombre ligado a todas las iniciativas de la época en el ámbito urbano, presidia la Sociedad Económica de Amigos del País y el Casino.

11 Garcia Martínez, S., "Evolución agraria de Villena hasta fines del siglo XIX". En Cuadernos de Geografía, núm. 1, Valencia, Universidad de Valencia, 1964, p. 199. En 1875, Moret contribuía por territorial 3.279 pesetas y Remisa 3.277 pesetas, ocupando el decimoquinto y decimoséptimo lugar, respectivamente, del total de los cincuenta mayores contribuyentes de la provincia. Boletín Oficial de la Provincia de Alicante, 9 de noviembre de 1875. 
Durante los años ochenta, Leach colaboró con el comerciante de Villena, Luis Penalva, ${ }^{12}$ en la apertura de pozos artesianos para riego, llegando a abrir hasta cinco. ${ }^{13} \mathrm{Al}$ plantearse la cuestión del abasto de aguas de Alicante, en torno a los años noventa, es cuando decide emplear todos sus recursos en la empresa: costea los estudios, paga el proyecto, hasta que, en Enero de 1897, las cuadrillas de obreros comienzan a instalar las tuberías.

En la financiación del proyecto intervienen capitales belgas que, junto a los británicos, constituían la mayor penetración foránea en el subsector del agua, en la economía española. La denominación de la sociedad coparticipadora respondía a la razón social Compagnie Genérale des Conduites d'eau, que se dedicaba, simultaneamente, a la fabricación de tubos y conducciones, como la mayoria de las empresas que obtenían las concesiones para instalación y suministro de aguas. ${ }^{14}$ Leach se reserva el aprovisionamiento, mientras que la compañía extranjera consigue el monopolio de abastecer de agua a la población durante sesenta años. En Octubre de 1898, se inaguran las nuevas acometidas bajo la razón social Sociedad de Aguas de Alicante, que absorbió a la anterior; compañía creada en Agosto de 1898. El capital ascendía a 3.000 .000 de francos y el domicilio social radicaba en Lieja. ${ }^{15}$ Juan Leach, artífice del proyecto ini-

Luis Penalva, según el rotativo de la época La Regeneración, era calificado como "acaudalado comerciante, con posesiones en Villena». Aunque vinculado a esta población, residía en Alicante, donde ejercía la exportación de vinos al por mayor. Miembro del republicanismo posibilista, ostentó la presidencia de la Junta de Gobierno de la Liga de Contribuyentes de Alicante y su Provincia, en 1895. Al mismo tiempo, actuaba como vocal en el Consejo de Administración de la Caja de Ahorros, siendo uno dè los mayores accionistas.

LÓPEz GómEZ, A., "Nuevos riegos en Valencia en el siglo XIX y comienzos del XX». En NADAL, J.y TORTELLA, G., Agricultura, comercio colonial y crecimiento económico en la España contemporánea, Barcelona, Ariel, 1974, p. 199. Costa CAMPi, M. T., "Iniciativas empresariales y capitales extranjeros en el sector servicios de la economía española durante la segunda mitad del siglo XIX". En Investigaciones Económicas, núm. 14, Madrid, Fundación del Instituto Nacional de Industria, enero-abril, 1981, pp. 59-60.

Costa Campi, M. T., op. cit., p. 59. 
cial conseguía con posterioridad realizar un buen negocio: participaba en los beneficios de la explotación por su condición de accionista, y asumía derechos en la gestión de la sociedad a través de su presencia en el Consejo de Administración. Acciones, todas, encaminadas, obviamente, a rentabilizar inversiones iniciales.

Al mismo tiempo, cesaba la actividad del Marqués de Benalúa y la The Alicante Water Work. Ya, en 1900, la sociedad Elche Water Work - compañia concesionaria del abastecimiento de aguas de esta ciudad, con sede en Londres - intentaba obtener de la firma belga la cesión de los derechos de suministro de agua a Alicante. El inicio de las conversaciones negociadoras se zanjaron sin llegar a un acuerdo definitivo. ${ }^{16}$

La acción de la sociedad concesionaria, durante sus primeros años de andadura, se orienta a un fin primordial: resarcirse de la inversión mediante la maximización del beneficio. Paralelamente, los conflictos no tardaron en surgir, especialmente, porque el reglamento elaborado por la compañía contemplaba fuertes tarifas por la instalación y cobranza de acometida domiciliaria. ${ }^{17}$ Otro punto contestado era la elevada tasa que debía satisfacerse por el agua destinada para fines industriales, tema que desató la protesta del pequeño y mediano artesanado urbano al incidir negativamente en sus actividades, ya de por sí bastante deprimidas por la coyuntura económica recesiva que les afectaba de modo especial. En la contrapartida a la concesión del monopolio, la empresa se comprometía a ceder gratuitamente 250 metros cúbicos diarios con destino a fuentes públicas. Dado, pues, que el precio del agua era sensiblemente elevado se produjo una masiva afluencia a los puntos de aprovisionamiento del común de los vecinos, lógicamente, con una mayor concurrrencia de las capas populares.

Esta situación provocó la rápida actuación de los representantes de la sociedad de aguas, instando al Ayuntamiento a que

Costa Campi, M. T., op. cit., p. 61.

Societé des eaux d'Alicante. Sociedad Anónima constituida por iniciativa de la Compagnie Genèrale des Conduites d'eau. Reglamento de contratación, Alicante, Imprenta de la viuda de R. Jordá, 1898, pp. 7-14. 
pusiera coto a los aguadores que, como actividad común, acarreaban el agua de las fuentes a los domicilios particulares. Se esgrimía como argumento central la violación de las cláusulas de la concesión. A pesar de las reticencias conservadoras al considerar el asunto como un servicio de particular a particular y que por lo tanto no conculcaba el vínculo contractual existente entre el municipio y la sociedad, la minoría liberal en el consistorio conseguía que la corporación se declarase competente en el tema. Por su parte, la oposición republicana acusaba a los sagastinos de proceder en connivencia con la compañía, apoyándose en la reiterada ausencia de los concejales liberales en los plenos donde no se discutían problemas relacionados con las aguas y, por contra, su ostensible presencia cuando tales cuestiones se dirimían. En cualquier caso, la concesionaria no alcanzaría sus propósitos de conseguir acabar con los aguadores.

Con anterioridad, en Septiembre de 1898, el abogado republicano y concejal, José Guardiola Ortiz, ya había planteado su total desacuerdo con el articulado del Reglamento de la Sociedad de Aguas de Alicante, y en su intervención ante el pleno municipal expresaba con nitidez la motivación principal que le inspiraba la mencionada compañía:

(...) No existe en mi animosidad alguna contra la Sociedad de las Aguas de Alicante, que cuenta con todas mis simpatías, y 10 digo bien alto porque yo jamás me he formado la ilusión de que los sueños que forman la referida sociedad vinieran á regenerar á Alicante, sino á realizar un negocion., ${ }^{18}$

\section{LOS TRANVIAS Y EL SECTOR ELECTRICO}

En 21 de Diciembre de 1892 se constituía, en la ciudad, la sociedad anónima Los Nueve, con el objeto de proceder a la colocación de tendidos para la ulterior explotación de los tranvías de Alicante y ramal al barrio de Benalúa. Se emitieron acciones por 250 pesetas cada una, cubiertas, en su mayoría, por comerciantes e industriales ubicados en la localidad. Entre el grupo brayado es nuestro. 
de promotores descollaba Amando Alberola, ${ }^{19}$ que ejerció la presidencia del Consejo de Administración hasta su fallecimiento, acaecido en Marzo de 1900. Alberola asumió, tras unos primeros años de resultados poco positivos, la medida de rebajar los precios de los billetes. Con ello, se propiciaba un incremento en el uso del transporte, por parte de la población, que conduciría, a la postre, al necesario saneamiento financiero de la empresa. En Julio de 1900, el Consejo de Administración pasó a presidirlo el catedrático de agricultura en el Instituto de Segunda Enseñanza y político conservador, Enrique Ferré Vidiella. Como vicepresidente actuaba José Carratalá Cernuda, armador de buques y consignatario; mientras que su hermano Gregorio simultaneaba el puesto de vocal con otros cargos en la Caja de Ahorros. El ex-alcalde conservador, José Soler Sánchez, desempañaba la intervención y Ernesto Vilar, comerciante republicano y amigo de Aberola, la secretaria. Cerrando el Consejo, Alfonso Sandoval -Barón de Petrés - ostentando una vocalía.

El descenso de las tarifas en el billetaje propició aumentos perceptibles en la recaudación: en 1898, se consiguió incrementar en 21.479 pesetas sobre el ejercicio económico anterior; en 1899, el alza producida sobre el precedente ascendió a 20.528 pesetas. Estas nuevas perspectivas no trastocaron los planes del Consejo de Administración que, a mediados de 1900, adopta posturas tendentes a la enajenación de la empresa a una compañía belga: aunque se habían invertido hasta 600.000 pesetas en la construcción de las líneas, el precio de venta se fijaba en 300.000 pesetas. Algunos miembros del Consejo comienzan a especular con la compra de acciones, llegando a adquirir un crecido número de éstas al precio de 20 pesetas; con lo cual, al ser vendidas a 100 pesetas, les reportaría un beneficio del $100 \times 100$ :

(...) Operación que haria honor a la perspicacia que para los negocios tienen esos genios, sino se diera la coincidencia de que

Alberola, comerciante de maderas y carbones minerales, ejercía como vocal y accionista de la Caja de Ahorros, socio de la Cámara de Comercio y presidente del Colegio Pericial mercantil. Destacado republicano en el Ayuntamiento y la Diputación, era miembro de las sociedades Los Nueve, concesionaria de los tranvías, y Los Diez Amigos, del ámbito de la construcción. 
esos acaparadores son los que mangonean en esa famosísima venta. ${ }^{20}$

Las presiones y visitas de emisarios a los accionistas se sucedían, haciendo hincapié a éstos en la depreciación que venían experimentando las acciones. Estas medidas iban encaminadas a conseguir el asentimiento de las dos terceras partes del capital que, según el Código de Comercio vigente, le era necesario al Consejo para realizar la operación de venta. Al compás de estas acciones disuasorias se retrasaba la convocatoria de Junta General, a fin de conseguir la mayor cantidad de acciones por parte de los implicados en la venta y lograr, de esta forma, mayoría en la asamblea. La Junta se convocó el 4 de Agosto de 1900 , ya que la entrega del tranvía estaba inicialmente preparada para Octubre del mismo año. El grueso del accionariado se lamentaba de los contenidos del llamamiento que señalaba la necesaria vinculación de los no asistentes a los acuerdos tomados en mayoría: gran número de pequeños inversores quedaban al margen de la convocación, toda vez que la fecha indicada correspondía a un día laborable e imposibilitaba la presencia de estos sectores profesionales en el acto.

Las pretensiones del Consejo no eran otras que encubrir intentos de reforma en los estatutos y reglamentos internos de la sociedad, con el propósito de hacer viable el proyecto de venta del tranvía a una empresa belga: la Compañia de Ferrocarriles Vecinales Españoles, $S$. A., que preveía el montaje de un tranvía a vapor de Alicante a Elche y Crevillente, partiendo, precisamente, desde el barrio de Benalúa, punto de entronque con las líneas locales. Las aspiraciones quedaban, pues, en el terreno de la especulación. Acciones por las que en principio se habían abonado 250 pesetas, ahora, "a fortiori", se las enajenaba por menos de 100 pesetas, porque -en opinión de un accionista anónimo- "así conviene a unos cuantos caballeros particulares", ${ }^{21}$ vaticinando "añádase, y esto el tiempo se encargará de aclararlo, que los citados consejeros disfrutarán de fueros, privilegios y otras ventajas en la empresa compradoran. ${ }^{22}$

20 "La venta del tranvía", El Republicano, Alicante, 27 de mayo de 1900.

21 Ibidem, 26 de julio de 1900.

22 Ibidem, 15 de julio de 1900. 
Observemos que algo similar había ocurrido con el abastecimiento de agua. En el caso de la sociedad explotadora de tranvías, las perspectivas económicas de que gozaba, en 1900, no podían ser mejores. Esta situación hacia viable, a tenor de los resultados obtenidos en 1898 y 1899, la máxima aspiración de los inversores: el reparto de dividendos. Según los cálculos elaborados por un accionista se podría repartir un dividendo del $5 \%$, afrontar anualmente la reposición de material, suprimir la deuda que arrastraban, cifrada en 170.000 pesetas, amortizándola y pagando los intereses en diez años; a la par, se podía crear un fondo de reserva para consolidar el capital social, suponiendo la ausencia de descensos en la recaudación. ${ }^{23} \mathrm{Si}$ el pretendido traspaso se intenta efectuar en un momento en que la empresa comienza a arrojar beneficios, esta situación refuerza el elemento especulativo con que actúan los patrocinadores de la venta. El elenco propulsor de la construcción primitiva del tranvía muestra, con esta actitud, su carácter oligárquico y la plena consciencia, no ya de satisfacer anhelos de la población sino, de efectuar sus propios negocios:

(...) algunos individuos de la directiva, lejos de entender al movimiento de opinión que se ha operado y rindiendo tan sólo culto á egoistas conveniencias, han puesto en juego relaciones de amistad, de parentesco, de dependencia, y hasta prestigios de autoridad, para someter á su voluntad á los accionistas que se han dejado doblegar á las imposiciones de un criterio guiado por el lucro particularísimo. ${ }^{24}$

Paralelamente a este tipo de operaciones, no podemos dejar de mencionar las implicaciones que, durante la época, tuvo la aplicación de la electricidad a los transportes. La implantación de los tranvías eléctricos, en muchas ciudades españolas, condujo a numerosas compañías de capital español a traspasar sus explotaciones e instalaciones a sociedades foráneas, principalmente, por la dificultad que entrañaba -ya por motivos técnicos, ya por la necesidad de incrementar las inversionesla reconversión de los tranvías de tracción animal. En Madrid, por ejemplo, el capital belga compró a Tranvias de Madrid todas

Ibidem, 2 de agosto de 1900. El subrayado es nuestro. 
sus líneas por ocho millones de pesetas, determinando sucesivas remodelaciones de las empresas explotadoreas madrileñas. ${ }^{25}$ En este mismo sentido, la concesionaria del tranvía de Novelda a Aspe gestionaba, en 1898, con una empresa también belga, el traspaso de su concesión. ${ }^{26}$

No resulta descartable que la hipotética conversión eléctrica de los tranvías de Alicante estuviera entre las aspiraciones de los consejeros y mayores accionistas que, en simbiosis con el incipiente sector eléctrico local, se enfrentaran a la enajenación del tranvía con un triple objetivo: adueñarse de ciertos lugares de decisión en la futura explotación extranjera, mediante el acaparamiento de acciones; abordar, desde la mayor envergadura de la empresa, un amplio haz de innovaciones necesarias; $y$, por último, conseguir el lanzamiento de las empresas eléctricas locales, en las que indistintamente intervienen como financieros, con el propósito de incrementar sus beneficios con el abastecimiento de la energía eléctrica necesaria para el funcionamiento de la red de tranvías.

Este conjunto de razones tuvieron que influir poderosamante en los esfuerzos que emplearon los especuladores de la oligarquia alicantina cuando tomaron las medidas oportunas para asegurarse un negocio que se perfilaba suficientemente lucrativo a medio plazo. No es de extrañar que sea precisamente, en Junio de 1900, - momento de mayor efervescencia en el tema de la posible venta del tranvía, que finalmente acabará realizándose-cuando a instancias del banquero y comerciante local, Ramón Guillén López, se intente construir una empresa de energía eléctrica con capital autóctono: La Electra Alicantina, S. A., instalada en pleno corazón urbano. En el correspondiente Consejo de Administración existe una notable presencia de consejeros y accionistas de la sociedad explotadora del tranvía; destaquemos las figuras del Barón de Petrés, el banquero Alfredo Salvetti o el importador de maderas Linares Such. En el

Costa Campi, M. T., op. cit., pp. 73-74. En el caso de Madrid, Valenzuela RuBIO, M., "Los orígenes de los transportes urbanos y de cercanias en Madrid". En Estudios Geográficos, núm. 130, Madrid, febrero, 1973, pp. 100-110. "Noticias del dia", El Correo, Alicante, 12 de julio de 1898. 
plazo de un mes se inician los trabajos de instalación de dinamos y motores, que colocan a la nueva compañía en disposición de generar fluido eléctrico a finales del verano de 1900; 27 fecha en que, cóincidentemente, se pretende la entrega del tranvía local a la sociedad belga. Los nexos de una y otra iniciativa explicitan los propositos de ambas intervenciones.

Sin embargo, las expectativas a seguir, en el sector eléctrico, trascienden el tema de los transportes: como consecuencia del finiquito del contrato municipal en el alumbrado público, dimanante del vínculo entre Ayuntamiento y Compañía Madrileña de Alumbrado y Calefacción por gas, quedaba abierta, de nuevo, la posibilidad de ofertar nuevos contratos por el alumbrado de la ciudad. ${ }^{28}$ En efecto, a raíz de la carrera tecnológica entre la alternativa gas o electricidad, saldada a favor de esta última, surgen otras empresas de suministro eléctrico urbano, como la que, a fines de 1890, patrocinan los comerciantes Hugo Prytz y Guillermo Campos Carreras, bajo la razón social, Compañia Prytz y Campos. ${ }^{29}$

El negocio eléctrico se encuentra también en disposición de competir con el gas en el equipamiento de luz en viviendas particulares, comercio e industria. De aqui que las posibilidades de rendimiento orienten ciertas inversiones hacia el sector. Con todo, la Compañía Madrileña del Alumbrado y Calefacción por gas, no desmantela sus instalaciones en la población sino que,

"Asuntos varios", La Regeneración, Alicante, 15 de junio de 1900. "Noticias locales", El Republicano, Alicante, 12 de julio de 1900.

28 La Compañía Madrileña de Alumbrado y Calefacción por gas, gozaba de los derechos del alumbrado de la ciudad, desde 1871, año en que se hizo con la concesión que disponía hasta entonces, la compañia holandesa de los hermanos Lebon. El contrato de la Madrileña se estableció por 30 años a contar desde 1870 , de modo que, en 1900, finalizaban sus derechos de aprovisionamiento.

29 Anuario Almanaque del Comercio, de la Industria, de la Magistratura y de la Administración. Año 1901, Madrid, Libreria Bailly-Baillerie, 1901. Prytz detentaba la dirección de una casa comercial, exportadora de almendras y frutas, denominada, Prytz, Carter y Cía. En 1900, consiguió el cargo de cónsul de Suecia y Noruega. Guillermo Campos Carreras, presidente de la Cámara de Comercio, intervenía en negocios habituales de tejidos y salazones. Asociado con Amando Alberola se dedicaba a la importación de carbones minerales y coke. Fue cónsul de Chile, Portugal y Brasil. 
fruto de la competencia que venía soportando, especialmente en Madrid, diversifica su producción hacia las cocinas a gas. ${ }^{30}$

\section{EL SECTOR DE LA CONSTRUCCION}

En íntima conexión con el auge demográfico se nos presenta el sector de la construcción. La presión de los efectivos po-. blacionales, sobre Alicante, hacian inevitable la renovación de áreas del casco antiguo y la expansión del denominado Ensanche; tema, este último, motivo de controversia entre la ciudad y los poderes públicos en los últimos años del siglo XIX. La Ley de Ensanche, sobre la base de los planos previstos por el municipio, no se aprobarían hasta Julio de 1896.

La coyuntura económica, caracterizada por un cierto estancamiento, repercute en el crecimiento de la actividad en la construcción. Si entre 1883 y 1894 el número de edificios erigidos traslucía un auge de relativa importancia - plasmado en las 3.914 fincas existentes en el primer año citado y las 4.289 censadas en el último-, los años posteriores serán de escaso movimiento, al menos hasta 1909-1910, en que se contabilizan 5.710 edificios. $^{31}$

En el período que comprende de 1880 1894, el auge de la edificación figura subordinado a los saneados negocios comerciales, ligados a la exportación vinícola y a los subsiguientes efectos inducidos sobre el artesanado y las capas populares ciudadanas. Es, pues, un momento decisivo en lo concerniente a un cambio en el aspecto urbanístico, propiciado por la ideología burguesa que remoza la concepción tradicional de la urbe. Fruto de esta mutación es la construcción del Barrio de Benalúa, situado en las inmediaciones del casco urbano. Para su realización se constituyó la sociedad denominada Los diez amigos, en Enero de 1883. Entre sus promotores destacan: el Marqués

Bahamonde Magro, A. y Toro Merida, J., Burguesía, especulación y cuestión social en el Madrid del siglo XIX, Madrid, Siglo XXI, 1978, p. 108.

31 INE, Anuario Estadístico de 1912. Principales actividades españolas, Madrid, 1912, pp. 280-281. 
de Benalúa; el alcalde conservador, José Soler Sánchez; Pedro García Andreu, comisionista y comerciante de vinos al por mayor; Gregorio Carratalá Cernuda, armador y consignatario; y, Amando Alberola. La erección de los bloques de viviendas obedecía, en gran parte, a los deseos de la burguesía media local de acomodarse en zonas alejadas del centro terciario y evitar, en la medida de lo posible, la coexistencia con las clases obreras. Santiago Varela, en un estudio sobre las obras del arquitecto Guardiola Picó - quien esbozó los planos- advierte en la tipología del diseño arquitectónico del barrio y sus edificios, unas pautas de distinción que conducen a inferir características burguesas en la posible clientela. ${ }^{32}$

Pero la ciudad, no sólo se expandía de forma horizontal - muy espasmódicamente - sino que lo hacía mucho más buscando la verticalidad. Las reformas y aumento de piso en edificaciones ya existentes, era un camino habitualmente emprendido para alojar a la población en crecimiento. De las 4.289 fincas asentadas en la localidad, en 1894, 1.287 lo eran de dos pisos; estas últimas, alcanzaban la cifra de 2.557, en 1909.

Cuando, en 1896, tras la aprobación del Ensanche se pueden acometer nuevas obras, la pésima situación económica - derivada de la sobreproducción vinícola, del alza de aranceles sobre trigos y harinas, con el subsiguiente encarecimiento de las subsistencias, y un incremento en cascada de los precios, conjugados con una presión fiscal en aumento constante- paralizará, casi por completo, el sector de la construcción. El testimonio de la Liga de Propietarios de Fincas Urbanas de Alicante confirmaba este receso:

De diez años a la fecha, la construcción de casas en esta localidad ha venido paralizándose, hasta el punto que hoy apenas se edifica, y son contadas las edificaciones emprendidas; y éstas son emplazadas sobre los mismos solares que existían otras ya ruinosas; y no se construyen edificios de nueva planta en el ensanche de la población. ${ }^{33}$

32 Varela Botella, S., "La obra arquitectónica de Guardiola Picó", en Revista del Instituto de Estudios Alicantinos, n. ${ }^{\circ} 30$, Alicante, Diputación Provincial, Mayo-Agosto, 1980, pp. 67 y ss.

33 "La edificación en Alicante", Boletín de la Liga de Propietarios de Fincas Urbanas de Alicante, n. ${ }^{\circ}$ 47, Alicante, septiembre de 1904. 
La comisión de hacienda del Ayuntamiento ya señalaba, en los presupuestos de 1898, un descenso con respecto al ejercicio del año anterior, por conceptos de nueva edificación: «28.750 pesetas que se consignan de menos por creer no se venderán los terrenos y parcelas que la Corporación tiene para su venta", justificándolo por "la crisis financiera que atraviesa el país". ${ }^{34}$

Como consecuencia de esta situación, la oligarquía urbana cierra filas desde el momento en que la coyuntura recesiva comienza a erosionar sus rentas, especialmente, las extraídas de los arrendamientos de fincas urbanas. No olvidemos que los principales inquilinos de sus propiedades - proletariado y artesanado local- están experimentando, en mayor medida que otros grupos, los efectos de la crisis. Crisis que origina la baja de los precios por alquiler y el impago de éstos, dando pie a múltiples cambios de vivienda, con el objetivo de burlar el deshaucio y el consiguiente embargo.

Es precisamente, en 1894, cuando fruto de este estado de cosas surge la Liga de Contribuyentes de Alicante y su Provincia que, en 1898, se trocaria en Liga de Propietarios de Fincas Urbanas de Alicante. En la primera Junta de Gobierno figuraba lo más granado de los "prohombres" de la ciudad: como presidente, Luis Penalva; tesorero, Román Bono, industrial próspero; vocales, Rafael Viravens, conservador; Florentino Elizaicin, del comité canóvista local; Ramón Guillén López, banquero y comerciante exportador; Francisco Linares Such, comerciante; y, el arquitecto municipal, José Guardiola Picó. Desde sus inicios, la Liga tendrá un objetivo prioritario: evitar a los propietarios los perjuicios derivados de la tramitación de expedientes judiciales por deshaucios, organizando un servicio a cargo de la propia entidad que acudiera en nombre de los asociados a los juzgados. En definitiva, se pretendía "conseguir ver sus fincas libres de

34 Presupuesto Municipal Ordinario de Ingresos y Gastos que ha de regir durante el año económico de 1898-1899, Alicante, Imprenta Costa y Mira, 1898, p. 98. 
aquellos inquilinos que, mirando con indiferencia el pago de los alquileres, al propietario son su constante y eterna pesadillan. ${ }^{35}$

No es, pues, de extrañar que el tema de los deshaucios ocupara la atención central en los planteamientos de la organiza ción. Algunos asociados serán portadores de medidas encaminadas a suprimir las pérdidas ocasionadas por el cese en la percepción de alquileres. En esta línea, Juan Antonio Masanet, uno de los mayores propietarios de fincas urbanas, proponía un conjunto de disposiciones que iban desde la elaboración de una lista de deshauciados, con expresión de nombres y apellidos - a publicar todos los meses en el Boletín de la sociedad- hasta la impresión de otra en la que constaran los inquilinos que abandonasen las viviendas sin haber cumplido sus compromisos, expresando las mensualidades que se habian dejado de cobrar por el propietario. Estas propuestas se complementaban haciendo una llamada a los asociados para que no establecieran arrendamientos verbales y demandasen fianzas a los inquilinos en previsión de posibles contingencias. ${ }^{36}$ Esta serie de providencias se encaminaban a la fusión de los detentadores de propiedades urbanas para actuar como grupo de presión, suficientemente cohesionado, con el objetivo de defender y proteger sus intereses: en este momento, haciendo frente a las negativas consecuencias que se dejaban sentir en sus niveles de renta.

A fines de 1905, una vez que la Liga ha cambiado su denominación, se habían recogido más de 3.000 nombres de inquilinos, unos deshauciados y otros que abandonaron las casas debiendo la suma estipulada en el alquiler. ${ }^{37}$ No obstante, estas actitudes de control se revelaran ineficaces, toda vez que la mis-

Liga de Contribuyentes de Alicante y su Provincia. Memoria leida en la Junta General celebrada en 27 de enero de 1895 por el secretario contador, D. Enrique María Ripoll, abogado del llustre Colegio de Alicante, Alicante, Impreta Costa y Mira, 1895, pp. 10 y ss.

36 «Proposición que presenta a la Junta de Gobierno de la Liga de Contribuyentes, el asociado D. Juan Antonio Masanet», Boletín de la Liga de Contribuyentes de Alicante y su Provincia, n. ${ }^{\circ} 2$, Alicante, Septiembre de 1894, p. 13.

37 Boletín de la Liga de Propietarios de Fincas Urbanas de Alicante, $n .^{\circ} 60$, Alicante, octubre de 1905, p. 236. 
ma organización reconocía que utodos dichos inquilinos se han instalado en nuevas habitaciones en esta capital". ${ }^{38}$ La mayoría de los propietarios que alojaban en sus fincas a los morosos no figuraban entre los asociados, lo cual muestra, no sólo el recelo hacia la desigual composición de la Liga, por parte de los pequeños propietarios, sino también la singular virulencia con que se estaba sintiendo la contracción de empleo entre la clase obrera, que obligaba a los dueños de las viviendas a aceptar inquilinos en las condiciones que fuese. Las posiciones avanzadas de los dirigentes de la Liga, en materia de arrendamientos urbanos, contrastan, durante este período, con las del grupo de pequeños propietarios, en el sentido de que estos últimos no hacían una interpretación legalista de la legislación sobre alquileres de fincas, ${ }^{39}$ sino que seguían las pautas consuetudinarias de los acuerdos verbales, pagos semanales y ausencia de fianzas. Mientras que los primeros contemplaban el sector de la construcción como una más de sus fuentes de acumulación de capitales, vía inversión, los segundos - los caseros de la época- lo hacían como complemento de sus ingresos. Se columbraba, pues, una posible dinamización del mercado de la vivienda en una ciudad en crecimiento a largo plazo, pero que, durante una década, padecía de evidentes síntomas de estancamiento.

Las justificaciones, desde el mismo seno de la Liga, al descenso de la construcción descansaban en la idea fundamental de la falta de colaboración de los trabajadores del sector -albañiles y maestros de obras - por sus continuadas exigencias. La paralización no provenía, según la asociación, de la ausencia de iniciativas ya que, en su opinión, existían capitales deseosos de afluir a la edificación:

Desde 1842, los propietarios poseían una capacidad de establecer los tipos de alquiler. Aún a pesar de quedar sometidos a revisiones contractuales periódicas, en la práctica los aumentos se decidian unilateralmente. Gaceta de Madrid, Madrid, 12 de abril de 1842. En Madrid, a los pocos meses de entrar en vigor la ley, los alquileres se habian duplicado, vid. BAHAMONDE, A. y TORO, J., "Datos para el estudio de la burguesía madrileña". En V. V. A. A. Crisis del Antiguo Régimen e industrialización en la España del siglo XIX, Madrid, Cuadernos para el Diálogo, 1977, pp. 230-231. 
¿A qué obedece la paralización? ¿Es que en Alicante no hay quien puede disponer de capital para dedicarlo á la edificación? Nada de eso. Nos consta y sabemos de buenas referencias que sobran elementos para constituir una compañía de urbanización. Que se puede disponer de los fondos necesarios para llevar á efecto las obras. ${ }^{40}$

A renglón seguido se exponía el verdadero argumento:

(...) lo que únicamente falta es buena voluntad en los albañiles para no pedir tantos absurdos en las horas de trabajo. ${ }^{41}$

Este tipo de razonamiento escondía el auténtico motivo: la inexistencia de condiciones necesarias para afrontar nuevas construcciones. Culpar a la clase obrera de la situación y plantear el tema en términos como «de seguir así llegará un día que nadie se atreverá á edificar y esto á quien más perjudica es a la clase obrera y de su actitud depende su ruina y miseria", ${ }^{42}$ suponía admitir que los trabajadores de la construcción constituían, en la época, una mano de obra especializada y en posición de plantear sus exigencias, lo que comportaría la disminución de los márgenes de beneficio del empresariado al soportar los efectos desagradables de las huelgas. Este argumento no era cierto, en la medida que las condiciones de trabajo del ramo de la construcción no diferían de las de otros sectores: tenían 9 horas de jornada, al igual que aserradores y pavimentadores; los salarios percibidos, en términos nominales, eran - a excepción de los oficiales que cobraban 4 pesetas diarias- bajos con relación a otros colectivos, 2,50 y 2 pesetas, igual que tipógrafos, estibadores portuarios o alfareros hidráulicos. ${ }^{43}$ Cabe destacar que las argumentaciones de los constructores estaban encaminadas a desprestigiar y culpar a la clase obrera de desanimar la inversión con sus pretensiones salariales y obtención de mejo-

40

43 AltamiRa, R., Derecho consuetudinario y economía popular en la provincia de Alicante, Madrid, Imprenta del Asilo del Sagrado Corazón de Jesús, 1905, pp. 51-55. 
ras de indole social. Lo cierto es que el hipotético inquilinato de las posibles fincas se debatía entre los problemas de desempleo, y la penosa situación obrera presagiaba un panorama de pésimas expectativas a los constructores. ${ }^{44}$ Además, el conjunto de trabajadores no se encontraba en disposición de adoptar posturas de fuerza en unos momentos en que el mercado de trabajo resultaba abundante y consiguientemente barato.

Los alquileres urbanos experimentaron, al doblar el siglo, un perceptible aumento con la reactivación estacional de la exportación. Sin embargo, el panorama de miseria e ịndigencia de amplias capas sociales de la ciudad seguía impregnando el ambiente de algunos barrios en los que se edificaban inmuebles de nula o escasa habitabilidad. Este era el caso del populoso San Antón, barriada de las más antiguas, se situaba en las inmediaciones de la Fábrica de Tabacos y recogía, en su mayoría, a las cigarreras de la mencionada fábrica. Guardiola Picó, arquitecto municipal inserto en las corrientes higienistas finiseculares, describía el barrio con estas afirmaciones:

(...) No se dan por ello vencidos los egoístas, que con su inmoderado afán de aumentar sus rentas, como propietarios de los terrenos, siguen a ciencia y paciencia de la Corporación Municipal edificando miserables casuchas, carentes en absoluto de condiciones de habitabilidad, pero útiles al parecer, según ellos, para seguir explotando á la clase proletaria, controlándoles los alquileres á diario ó por semanas, según sean las condiciones relativas de los individuos que las ocupan, manteniendo con este sistema, antihumanitario la anárquica urbanización que, por regla general, se observa en este barrio tan importantísimo por el número de vecinos que contiene. ${ }^{45}$

Las concomitancias entre propietarios y Ayuntamiento quedaban reforzadas y patentes con el subsiguiente argumento

44 Una aproximación a las duras condiciones de vida del proletariado de la ciudad de Alicante, en este período, la hemos esbozado en VIDAL OLIVARES, J., "Apuntes sobre la situación social de la clase obrera alicantina durante la Restauración (1887-1905)", Actas del VII Congreso Nacional de Historia de la Medicina, Alicante. abril de 1983. (En prensa).

45 Guardiola Picó, J., Reformas de Alicante para el siglo XX, Alicante, Imprenta de Luis Esplá, 1909, p. 42. 
del mismo autor: «...estas pocilgas que la avaricia desenfrenada construye valiéndose de los descuidos incomprensibles de nuestros Ayuntamientos". ${ }^{46}$ Fundir intereses comunes, manejando las palancas del poder municipal, funcionaban con entera efectividad a lo largo de las últimas décadas de la centuria y aun de las primeras del siglo XX.

\section{CONCLUSIONES}

El agua, los tranvías, el sector eléctrico y la construcción se revelan como focos de atracción de capitales. Las iniciativas se configuran atendiendo a un carácter básicamente especulativo, con un proceso común a todas ellas: se advierte la expectativa de rentabilidad, se acometen las primeras fases de los proyectos y, finalmente, se inhiben en la continuidad de las empresas para acabar traspasando total o parcialmente (caso del agua o los tranvías) - asegurándose una futura presencia en la gestión - sus sociedades a compañías con fuerte participación de capital extranjero.

El sector eléctrico tiene características distintas ya que, al ser un negocio que comienza, cuenta con una segura optimización de beneficio. La construcción no verificará su lanzamiento hasta bien entrado el siglo $X X$, lo que no invalida su configuración en un auténtico negocio que ya acapara la inversión de capitales.

Quienes protagonizan estas iniciativas mantienen un denominador común: pertenecen a una clase social dinámica - la burguesía- que controla los mecanismos institucionales de la época, Ayuntamiento fundamentalmente. Aunque entre ellos existen diferencias internas, que políticamente se plasman en las distintas opciones, actúan con cierta homogeneidad. En este sentido, el sistema del turno no es más que una fachada, aunándose, en su interior, intereses económicos y políticos, que si no son plenamente coincidentes al menos sí son convergentes. Lo que buscan, pues, es una diversificación de sus in-

Guardiola Pico, J., op. cit., p. 43. 
gresos, especialmente aquellos que poseen una visión económica más avanzada, como Amando Alberola - quien asistió a la Asamblea de Cámaras de Comercio de Zaragoza, en representación por la de Alicante, allí hizo amistad con Costa y Basilio Paraíso, siendo uno de los mayores instigadores del movimiento opositor a los presupuestos de Villaverde en 1899-1900-, Juan Leach - defensor a ultranza del librecambismo-, Luis Penalva o Ramón Guillén López. Todos ellos formaban parte de una burguesía comercial penetrada por fuertes intereses agrarios, pero desde coordenadas urbanas. Contaban para ello con experiencia en la puesta en marcha de innovaciones en otros sectores como la búsqueda de agua para riego.

El tibio republicanismo de algunos, que políticamente no les favorecía pero que tampoco les perjudicaba - por difuminar, tales diferencias los niveles de estima social-, les otorgaba un cariz de progreso con respecto a las posiciones del conservadurismo o el liberalismo - dos caras de una misma moneda- que se nutrían únicamente de sectores moderados que extraían sus ingresos, casi de modo exclusivo, de la propiedad agraria de signo rentista. Con todo, la adscripción política republicana de estos hombres no les impediría utilizar el poder de las instituciones, copadas por el tinglado, para sus fines: obtener concesiones, contratas, etc. Buena prueba es que figuraron en los Consejos de Administración junto a los alcaldes de corte conservador, como José Soler Sánchez, en 1883, o el Barón de Petrés, en 1900. No formaban parte del bloque de poder pero se servían de él para sus propios objetivos; en otras palabras, no integraban la clase dirigente pero participaban de la dominante.

Calificar de "aristocracia financiera" a este sector de la clase dominante, cuyo fin primordial no era otro que ampliar sus tasas de beneficio a costa de negocios que ofrecian a corto plazo una rentabilidad clara y, fundamentalmente, segura, garantizada mediante la oportuna inversión, ha trascendido del terreno de la mera hipótesis de trabajo para acabar corroborando su existencia.

A pesar de esta importante característica, no olvidemos que la burguesía alicantina continuó con sus tradicionales tran- 
sacciones ligadas al comercio de exportación e importación, participó en la financiación de las guerras de Cuba y Puerto Rico y colocó capitales en los empréstitos lanzados por los gobiernos de la Restauración, buscando la estabilidad que ofrecía la deuda pública. Desde la lógica interna de este sector no parece desacertado su comportamiento. En este sentido, según nuestra opinión, se debe empezar a explicar, con toda su complejidad histórica, la ausencia de una ideología específicamente industrializadora en el seno de la oligarquía mercantil portuaria y de sus grupos subalternos, que han protagonizado hegemónicamente la historia de la ciudad de Alicante -dentro del contexto más amplio y general del País Valenciano-durante el siglo XIX y XX. 